\title{
A vector system for fast-forward in vivo studies of the ZAR1 resistosome in the model plant Nicotiana benthamiana
}

\author{
Adeline Harant, Toshiyuki Sakai, Sophien Kamoun*, Hiroaki Adachi* \\ The Sainsbury Laboratory, University of East Anglia, Norwich Research Park, Norwich NR4 \\ 7UH, UK. *For correspondence: sophien.kamoun@tsl.ac.uk; hiroaki.adachi@tsl.ac.uk
}

\section{ABSTRACT}

Nicotiana benthamiana has emerged as a complementary experimental system to Arabidopsis. It enables fast-forward in vivo analyses primarily through transient gene expression and is particularly popular in the study of plant immunity. Recently, our understanding of NLR plant immune receptors has greatly advanced following the discovery of Arabidopsis ZAR1 resistosome. Here, we describe a novel vector system of 52 plasmids that enables functional studies of the ZAR1 resistosome in $\boldsymbol{N}$. benthamiana. We showed that ZAR1 stands out among the coiled coil class of NLRs for being highly conserved across distantly related dicot plant species and confirmed NbZAR1 as the $N$. benthamiana ortholog of Arabidopsis ZAR1. NbZAR1 triggers autoimmune cell death in $N$. benthamiana and this activity is dependent on a functional $\mathrm{N}$-terminal $\alpha 1$ helix. C-terminally tagged NbZAR1 remains functional in $\boldsymbol{N}$. benthamiana thus enabling cell biology and biochemical studies in this plant system. We conclude that the NbZAR1 open source plasmids form an additional experimental system to Arabidopsis for in planta resistosome studies.

\section{INTRODUCTION}

Nicotiana benthamiana has developed into a popular model system in plant biology, particularly for the study of plant immunity. The appeal of $N$. benthamiana as an experimental system is primarily due to agroinfiltration, a rapid transient protein expression method that enables cell biology, biochemistry, protein-protein interaction analyses and other in vivo experiments (Goodin et al., 2008). In addition, $N$. benthamiana is a member of the asterid group of flowering plants and as such is relatively distant from the classic model plant Arabidopsis thaliana, which belongs to the rosid group. Therefore, $N$. benthamiana is a complementary experimental system to Arabidopsis that also allows for a broader perspective into the evolution of molecular mechanisms in dicot plants.

Plants use nucleotide-binding leucine-rich repeat (NLR) proteins to mount innate immunity against invading pathogens. NLRs are intracellular receptors that detect host cell-translocated pathogen effectors and activate a hypersensitive cell death response that is a hallmark of plant immunity. The recent elucidation of the structures of the inactive and active complexes formed by the Arabidopsis NLR protein ZAR1 (HOPZ-ACTIVATED RESISTANCE1) with its partner receptor-like cytoplasmic kinases (RLCKs) is a major breakthrough in understanding how these immune receptors are activated and function. Activated ZAR1 forms a wheel-like pentamer, termed resistosome, that undergoes a conformational switch - the death switchto expose a funnel-shaped structure formed by the N-terminal $\alpha 1$ helices (Wang et al., 2019a; 2019b). The ZAR1 resistosome was proposed to mediate cell death directly by translocating into the plasma membrane through the funnel-like structure and perturbing membrane integrity similar to pore-forming toxins (Wang et al., 2019b). The $\mathrm{N}$-terminal $\alpha 1$ helix matches a sequence motif known as MADA motif that is functionally conserved across $\sim 20 \%$ of coiled- 
coil (CC)-type plant NLRs (Adachi et al., 2019). This indicates that the ZAR1 death switch mechanism may be widely conserved across plant species. Mutations in surface-exposed residues within the $\alpha 1$ helix/MADA motif impair cell death and disease resistance mediated by ZAR1 and other MADA-CC-NLRs (Wang et al., 2019b; Adachi et al., 2019).

Here, we describe a Golden Gate compatible vector system (pZA) that enables functional studies of the ZAR1 resistosome in $N$. benthamiana. Golden Gate enables modular cloning through assembly of DNA fragments in one-step Type IIS restriction enzyme reactions. Consistent with previous reports (Baudin et al. 2017; 2019), we confirmed that Arabidopsis ZAR1 (AtZAR1) does not cause hypersensitive cell death in $N$. benthamiana when expressed on its own and that $N$. benthamiana carries an ortholog of ZAR1 (NbZAR1). We developed and validated the pZA plasmid collection and share it as an open source resource that should prove useful for functional and comparative studies of NLR resistosomes in plants.

\section{RESULTS AND DISCUSSION}

\section{ZAR1 is conserved across distantly related dicot plant species}

Baudin et al. (2017) previously reported two orthologs of Arabidopsis ZAR1 and named them NbZAR1 and NbZAR2. We confirmed their findings by performing phylogenetic analyses of NLR proteins using the NB-ARC (nucleotide-binding adaptor shared by APAF-1, certain $R$ gene products and CED-4) domain from 5 dicot plant species (Arabidopsis, cassava, sugar beet, tomato and $N$. benthamiana) representing three major clades of dicot plants (rosids, aterids and Caryophyllales). The resulting phylogenetic tree included 829 NLRs, which expectedly clustered into the well-defined NLR classes (Figure 1A). Arabidopsis ZAR1 (AtZAR1, AT3G50950) fell within a well-supported CC-NLR subclade that included NbZAR1 (NbS00000462g0011), NbZAR2 (NbS00013646g0007) and one gene each from the three other dicot plant species (Figure 1A). As previously reported (Baudin et al. 2017), NbZAR2 gene is truncated in the reference $N$. benthamiana genome (Figure 1 -figure supplement 1 ). The other four genes, NbZAR1, Manes.02G097400 (MeZAR1), Bv9 203570 geqf.t1 (BvZAR1) and Solyc02g084890 (SIZAR1), code for CC-NLR proteins of similar length to AtZAR1, suggesting them as ZAR1 orthologs in each dicot plant species (Figure 1-figure supplement 1).

Based on our experience, ZAR1 seemed atypical among NLRs for having well-defined orthologs across unrelated dicot species. To directly evaluate ZAR1 conservation relative to other CC-NLRs, we calculated the phylogenetic (patristic) distance between each of the 47 Arabidopsis CC-NLRs and their closest gene from the other plant species based on the phylogenetic tree (Figure 1A). Interestingly, AtZAR1 stood out among the CC-NLRs as having the shortest phylogenetic distance to its four orthologs (Figure 1B). Similarly, in a reverse analysis where we plotted the phylogenetic distance between each of the $153 \mathrm{~N}$. benthamiana CC-NLRs to their closest gene from the other species, NbZAR1 again stood out as being exceptionally conserved across all five examined species relative to other $N$. benthamiana CC-NLRs (Figure 1-figure supplement 2). Multiple alignments of the ZAR1 orthologs from the examined species confirmed the relatively high conservation of ZAR1 with pair-wise sequence similarities ranging from $58 \%$ to $86 \%$ across the full NLR protein (Figure 1 -figure supplement 1 ). Overall, these analyses confirm NbZAR1 as the $N$. benthamiana ortholog of AtZAR1 and reveal ZAR1 as possibly the most widely conserved CC-NLR in dicot plants. 


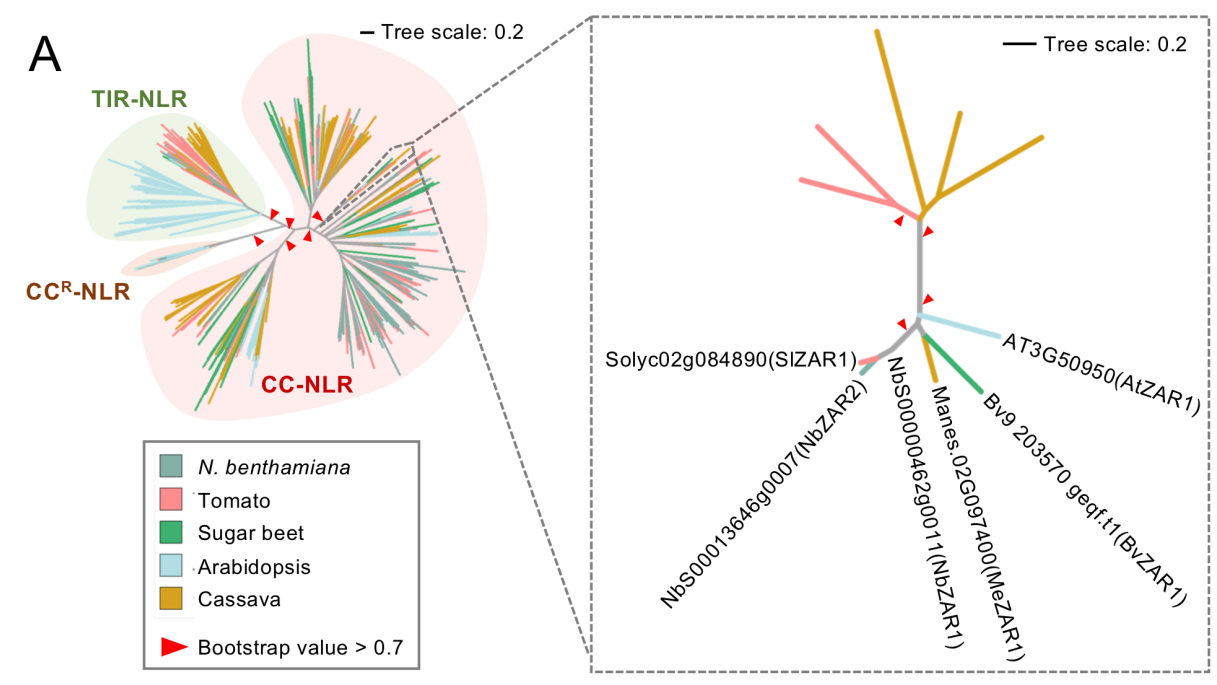

B

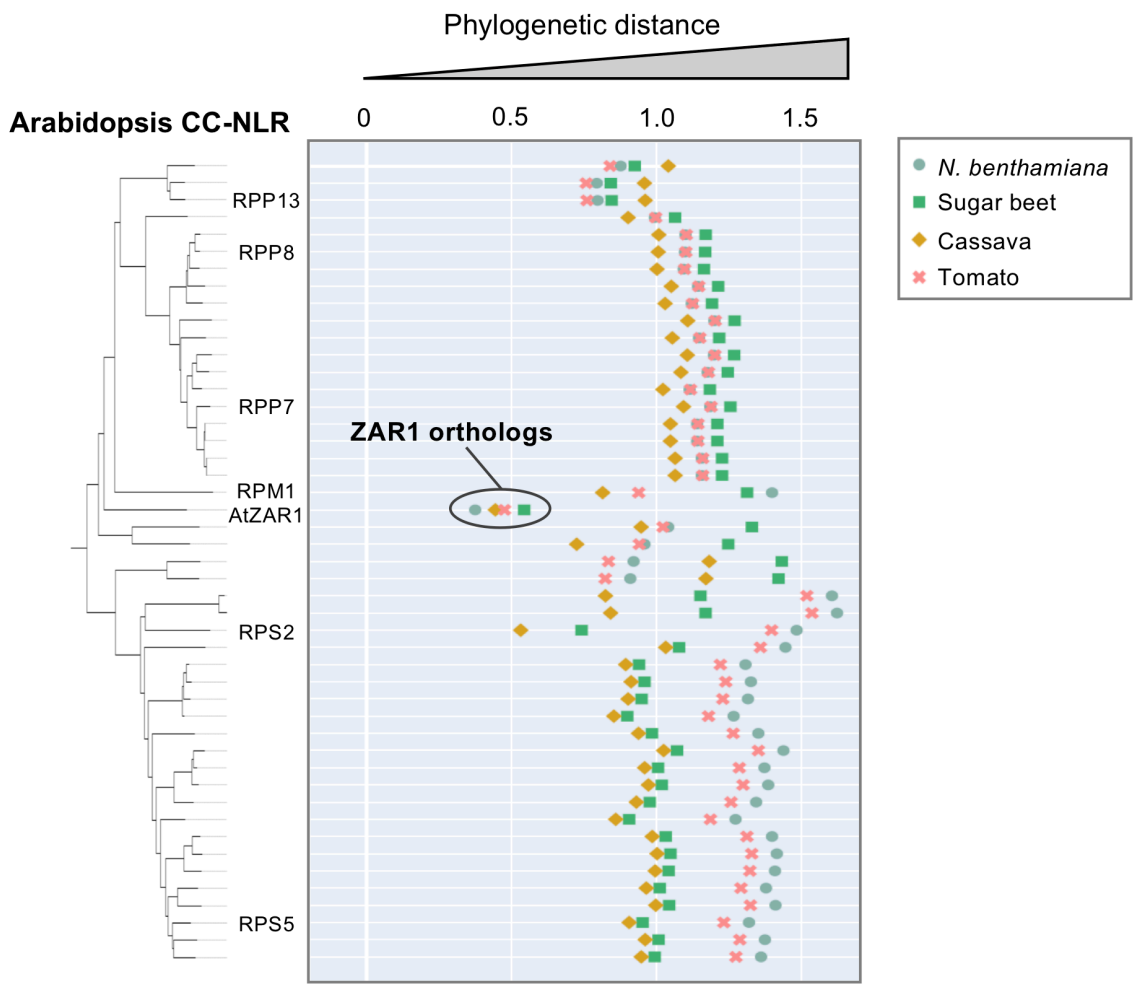

Figure 1. ZAR1 is a conserved CC-NLR across distantly related dicot plant species. (A) ZAR1 forms a small subclade that is composed of orthologous genes from distantly related dicot plant species. The phylogenetic tree was generated in MEGA7 by the neighbour-joining method using NB-ARC domain sequences of 829 NLRs identified from N. benthamiana (NbS-), tomato (Solyc-), sugar beet (Bv-), Arabidopsis (AT-) and cassava (Manes-) (left panel). The ZAR1 subclade phylogenetic tree is shown on the right panel. Each branch is marked with different colours based on plant species. Red arrow heads indicate bootstrap support $>0.7$ and is shown for the relevant nodes. The scale bars indicate the evolutionary distance in amino acid substitution per site. Amino acid sequences of the full-length ZAR1 orthologs can be found in Figure 1-figure supplement 1. (B) AtZAR1 is highly conserved among dicot CC-NLRs. The phylogenetic (patristic) distance of two CC-NLR nodes between Arabidopsis and other plant species were calculated from the NB-ARC phylogenetic tree in A. The closest patristic distances are plotted with different colours based on plant species. Representative Arabidopsis NLRs are highlighted. The closest patristic distances of two CC-NLR nodes between $N$. benthamiana and other plant species can be found in Figure 1-figure supplement 2. 


\section{Golden Gate compatible ZAR1 plasmids for in vivo resistosome studies}

The Golden Gate cloning system enables rapid and high throughput assembly of multiple sequence modules, such as promotor, terminator or tags into a common vector (Patron et al., 2015). To facilitate in vivo resistosome studies using this cloning strategy, we first introduced synonymous mutations to Bpil restriction enzyme sites in the coding sequence of AtZAR1 and NbZAR1 to make them both Golden Gate compatible and enable their transfer into a variety of Agrobacterium tumefaciens binary vectors for in planta protein expression. We cloned the genes into the Golden Gate compatible vector pUC8-Spec (pZA1, 5, 9 and 13 in Table 1). Each coding sequence was flanked by $B s a l$ restriction enzyme sites and overhang sequences for optimal Golden Gate reactions (Table 1-figure supplement 1).

We generated autoactive and inactive versions of full-length ZAR1 by mutating the MHD and MADA motifs, which are both conserved across ZAR1 orthologs (Figure 1-figure supplement 1). Whereas mutation from aspartic acid (D) to valine $(V)$ in the MHD motif generally makes full-length NLRs autoactive (Tameling et al., 2006), mutations in the N-terminal MADA motif impair NLR cell death activity (Wang et al., 2019b; Adachi et al., 2019). We generated a mutant series of AtZAR1 and NbZAR1, namely MHD mutants (AtZAR1 ${ }^{\text {D489V }}$ and NbZAR1 ${ }^{\text {D481V }}$ ), MADA mutants (AtZAR1 ${ }^{\text {L17E }}$ and NbZAR1 ${ }^{\text {L17E}}$ ) and MADA/MHD mutants (AtZAR1 ${ }^{\text {L17E/D489V }}$ and NbZAR1 ${ }^{\mathrm{L} 17 \mathrm{E} / \mathrm{D} 481 \mathrm{~V}}$ ). We cloned the variant genes into pUC8-Spec (pZA2-4, 6-8, 10-12 and 14-16 in Table 1) and assembled the genes into binary vector plasmids without tags or with the Cterminal tags 4xMyc, 6xHA and eGFP (pZA17-52 in Table 1). This collection of 52 plasmids forms an open access resource for in planta ZAR1 resistosome studies.

\section{Unlike Arabidopsis ZAR1, NbZAR1 triggers autoimmune cell death in $\mathbf{N}$. benthamiana.}

To validate the ZAR1 constructs we generated, we first used agroinfiltration to transiently express wild-type ZAR1 and the MHD mutants AtZAR1 $1^{\text {D489V }}$ and NbZAR1 ${ }^{\text {D481V }}$ in $N$. benthamiana leaves (Figure 2A). As recently reported by Baudin et al. (2019), AtZAR1 did not trigger macroscopic cell death in $N$. benthamiana leaves even when the full-length protein carries the D489V mutation in the MHD motif (Figure 2B and 2C). In contrast, NbZAR1 caused macroscopic cell death when the MHD mutant NbZAR1 $1^{\text {D481V }}$ was expressed in $N$. benthamiana leaves (Figure 2D and 2E). NRC4 was used as a control MADA-CC-NLR, because its MHD mutant NRC4 ${ }^{\mathrm{D} 478 \mathrm{~V}}$ causes autoactive cell death in N. benthamiana leaves (Adachi et al., 2019). Our results indicate that unlike Arabidopsis ZAR1, full-length NbZAR1 can be made autoactive in $N$. benthamiana through mutation of the MHD motif. These results are consistent with a previous report that AtZAR1 causes hypersensitive cell death in $N$. benthamiana when coexpressed with the Arabidopsis RLCK AtZED1 (Baudin et al., 2017). We conclude that unlike AtZAR1, NbZAR1 is probably compatible with endogenous RLCKs and can therefore display autoactivity when expressed on its own in N. benthamiana leaves.

\section{NbZAR1 autoimmune cell death is dependent on its $\mathbf{N}$-terminal $\alpha 1$ helix}

Next, we tested whether NbZAR1 requires an intact N-terminal $\alpha 1$ helix/MADA motif for triggering autoactive cell death. We expressed the double MADA/MHD mutant NbZAR1 $1^{\text {L17E/D481V }}$ in $N$. benthamiana leaves using agroinfiltration and observed that the leucine 17 to glutamic acid mutation significantly reduced the cell death activity compared to 
A

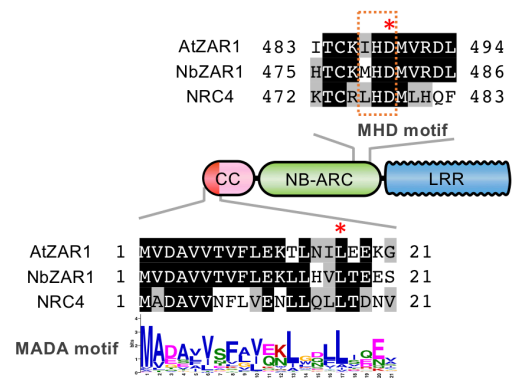

B

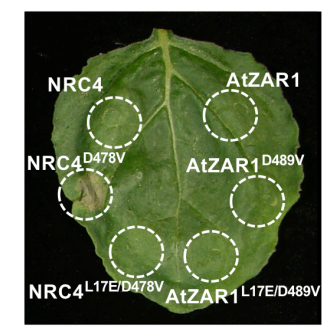

$\mathrm{D}$
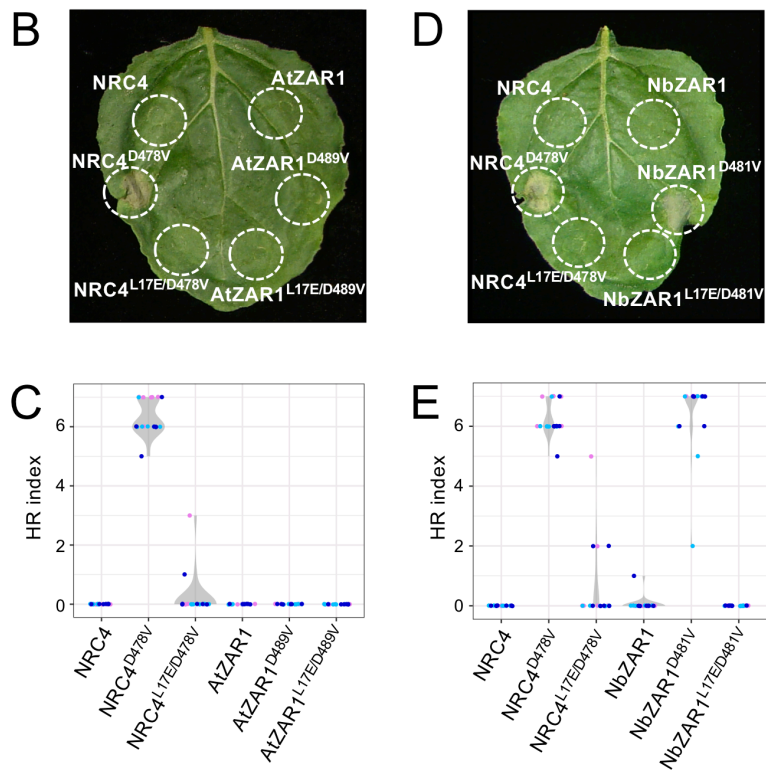

Figure 2. NbZAR1 triggers autoimmune cell death in $N$. benthamiana leaves and requires an intact MADA motif for autoactivity. (A) Schematic representation of substitution sites in AtZAR1, NbZAR1 and NRC4. Mutated sites are shown with red asterisks on the sequence alignment. (B and D) Cell death observed in $N$. benthamiana leaves after expression of ZAR1 mutants. $N$. benthamiana leaf panels expressing nonepitope-tagged wild-type and variant proteins of AtZAR1 and NbZAR1 were photographed at 5 days after agroinfiltration. (C and E) Violin plots showing cell death intensity scored as an HR index based on three independent experiments.

NbZAR1 ${ }^{\text {D481V }}$ (Figure 2D and 2E). This result indicates that an intact $\mathrm{N}$-terminal $\alpha 1$ helix is necessary for NbZAR1 ${ }^{\text {D481V }}$ autoactivity. Given that the $\alpha 1$ helix forms a funnelshaped structure that is a key structural component of activated ZAR1 resistosome and its translocation into the plasma membrane (Wang et al., 2019b), we conclude that the NbZAR1 ${ }^{\text {D481V }}$ experimental system recapitulates the resistosome model in $N$. benthamiana.

\section{C-terminally tagged NbZAR1 is functional in N. benthamiana}

$N$. benthamiana agroinfiltration is a powerful method for in vivo cell biology, biochemistry and protein-protein interaction analyses, but this experimental system requires that the target protein remains functional and intact after fusion to an epitope or fluorescent tag (Goodin et al., 2008; Bally et al., 2018). We therefore set out to determine the degree to which NbZAR1 can tolerate protein tags (Table 1). We focused on C-terminal tags, given that $\mathrm{N}$ terminal tag fusion is known to interfere with the AtZAR1 cell death activity (Wang et al., 2019b). We tested NbZAR1 ${ }^{\text {D481V }}$ constructs fused to three different tags, 4xMyc, 6xHA and eGFP by agroinfiltration. In all three cases, NbZAR1 ${ }^{\mathrm{D} 481 \mathrm{~V}}$ retained the capacity to trigger autoactive cell death although the response was weaker than the non-epitope-tagged NbZAR1 positive control (Figure 3A to 3F). We also showed by western blot analyses that these C-terminally tagged NbZAR1 accumulated at detectable levels in $N$. benthamiana leaves and generally formed a single band indicative of minimal protein degradation (Figure $3 G$ to 31). We conclude that C-terminal tagging of NbZAR1 doesn't dramatically interfere with the activity and integrity of this NLR protein.

\section{Towards in vivo studies of the ZAR1 resistosome}

We conclude that the open source pZA plasmid resource we developed can serve as a valuable experimental system for in vivo resistosome studies in $N$. benthamiana that 

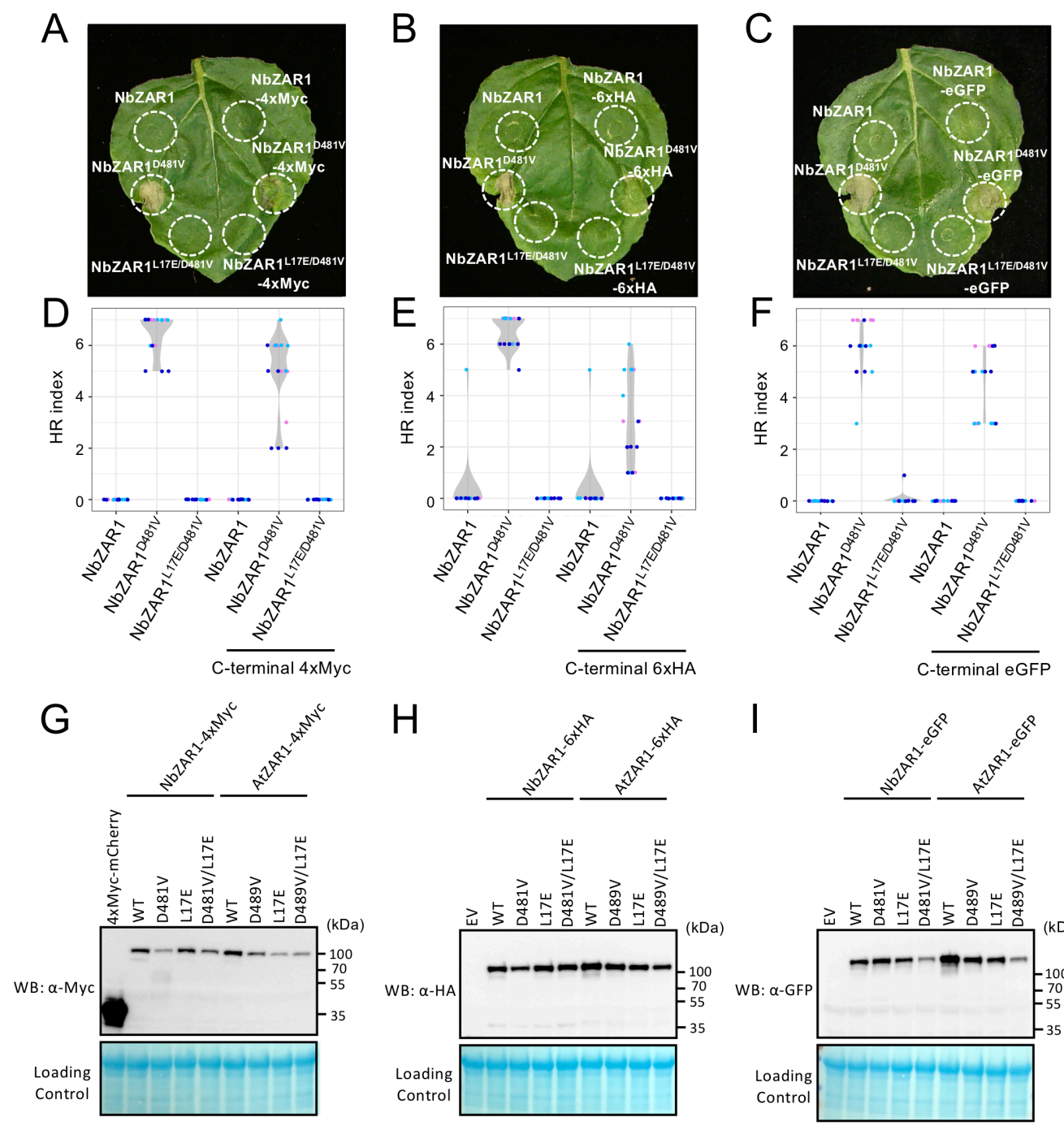

Figure 3. C-terminal tagged NbZAR1 triggers autoimmune cell death in $\mathbf{N}$. benthamiana leaves. (A-C) Cell death observed in $N$. benthamiana leaves after expression of ZAR1 mutants. $N$. benthamiana leaf panels expressing wild-type and variant proteins of NbZAR1 with C-terminal 4xMyc, 6xHA or eGFP tag were photographed at 5 days after agroinfiltration. (D-F) Violin plots showing cell death intensity scored as an HR index based on three independent experiments. (G-I) In planta protein accumulation of AtZAR1 and NbZAR1 variants. For anti-Myc, anti-HA and anti-GFP immunoblots of AtZAR1, NbZAR1 and the mutant proteins, total proteins were prepared from $N$. benthamiana leaves at 2 days after agroinfiltration. Empty vector control is described as EV. Equal loading was checked with Reversible Protein Stain Kit (Thermo Fisher).

complements the Arabidopsis system and provide a foundation for future studies. The autoimmune NbZAR1 ${ }^{\text {D481V }}$ mutant can be readily expressed by agroinfilitration in $N$. benthamiana leaves and assayed for cell death activity. NbZAR1 ${ }^{\text {D481V }}$ tolerates different Cterminal tags enabling in planta cell biology, biochemical and protein-protein interactions studies of the ZAR1 resistosome. These tags do not dramatically disturb the activity of NbZAR1 ${ }^{\text {D481V }}$ and may not affect recruitment of endogenous RLCK partners that are potentially necessary for its function.

The pZA toolkit complements existing assays in Arabidopsis. Of particular interest is the visualization of activated NLR oligomers in vivo. Recently, 900 kDa complexes associated with activated AtZAR1 and another Arabidopsis MADA-CC-NLR RPP7 were detected using Blue Native polyacrylamide gel electrophoresis and gel filtration (Li et al., 2020; Hu et al., 
bioRxiv preprint doi: https://doi.org/10.1101/2020.05.15.097584; this version posted May 16,2020 . The copyright holder for this preprint (which was not certified by peer review) is the author/funder, who has granted bioRxiv a license to display the preprint in perpetuity. It is made available under aCC-BY 4.0 International license.

2020). N. benthamiana agroinfiltration offers a rapid and effective alternative expression system to the Arabidopsis protoplast and transgenic expression systems used by Li et al. (2020) and Hu et al. (2020).

ZAR1 stands out among CC-NLRs for being widely conserved across dicot plants but it remains unknown how ZAR1 orthologs vary in their molecular and biochemical activities. The pZA system enables evolutionary studies of the ZAR1 resistosome. Comparative analyses between AtZAR1 and NbZAR1 would help answer questions about the evolution of the resistosome as a mechanism to trigger NLR-mediated immunity.

\section{MATERIALS AND METHODS}

\begin{tabular}{|c|c|c|c|c|}
\hline \multicolumn{5}{|c|}{ Key Resources Table } \\
\hline $\begin{array}{l}\text { Reagent type } \\
\text { (species) or } \\
\text { resource }\end{array}$ & Designation & $\begin{array}{l}\text { Source or } \\
\text { reference }\end{array}$ & Identifiers & $\begin{array}{l}\text { Additional } \\
\text { information }\end{array}$ \\
\hline $\begin{array}{l}\text { Gene } \\
\text { (Arabidopsis } \\
\text { thaliana) }\end{array}$ & $\begin{array}{l}\text { Arabidopsis } \\
\text { genome sequence }\end{array}$ & $\begin{array}{l}\text { https://www.arap } \\
\text { ort.org/ }\end{array}$ & Araport11 & $\begin{array}{l}\text { Materials and } \\
\text { Methods: } \\
\text { Bioinformatic and } \\
\text { phylogenetic } \\
\text { analyses }\end{array}$ \\
\hline $\begin{array}{l}\text { Gene ( } N \text {. } \\
\text { benthamiana) }\end{array}$ & $\begin{array}{l}\text { N. benthamiana } \\
\text { genome sequence }\end{array}$ & $\begin{array}{l}\text { Sol Genomics } \\
\text { Network } \\
\text { (https://solgenomi } \\
\text { cs.net/) }\end{array}$ & $\begin{array}{l}\text { N. benthamiana } \\
\text { Genome v0.4.4 }\end{array}$ & $\begin{array}{l}\text { Materials and } \\
\text { Methods: } \\
\text { Bioinformatic and } \\
\text { phylogenetic } \\
\text { analyses }\end{array}$ \\
\hline $\begin{array}{l}\text { Gene (Solanum } \\
\text { lycopersicum) }\end{array}$ & $\begin{array}{l}\text { Tomato genome } \\
\text { sequence }\end{array}$ & $\begin{array}{l}\text { Sol Genomics } \\
\text { Network } \\
\text { (https://solgenomi } \\
\text { cs.net/) }\end{array}$ & $\begin{array}{l}\text { Tomato ITAG } \\
\text { release } 2.40\end{array}$ & $\begin{array}{l}\text { Materials and } \\
\text { Methods: } \\
\text { Bioinformatic and } \\
\text { phylogenetic } \\
\text { analyses }\end{array}$ \\
\hline $\begin{array}{l}\text { Gene (Manihot } \\
\text { esculenta) }\end{array}$ & $\begin{array}{l}\text { Cassava genome } \\
\text { sequence }\end{array}$ & $\begin{array}{l}\text { Phytozome v13 } \\
\text { (https://phytozom } \\
\text { e- } \\
\text { next.jgi.doe.gov/) }\end{array}$ & $\begin{array}{l}\text { Manihot esculenta } \\
\text { v7.1 }\end{array}$ & $\begin{array}{l}\text { Materials and } \\
\text { Methods: } \\
\text { Bioinformatic and } \\
\text { phylogenetic } \\
\text { analyses }\end{array}$ \\
\hline $\begin{array}{l}\text { Gene (Beta } \\
\text { vulgaris) }\end{array}$ & $\begin{array}{l}\text { Sugar beet } \\
\text { genome sequence }\end{array}$ & $\begin{array}{l}\text { http://bvseq.molg } \\
\text { en.mpg.de/index.s } \\
\text { html }\end{array}$ & RefBeet-1.2 & $\begin{array}{l}\text { Materials and } \\
\text { Methods: } \\
\text { Bioinformatic and } \\
\text { phylogenetic } \\
\text { analyses }\end{array}$ \\
\hline \multirow[t]{2}{*}{$\begin{array}{l}\text { Gene } \\
\text { (Arabidopsis } \\
\text { thaliana) }\end{array}$} & AtZAR1 & $\begin{array}{l}\text { Araport11 } \\
\text { (https://www.arap } \\
\text { ort.org/) }\end{array}$ & AT3G50950 & \multirow{2}{*}{$\begin{array}{l}\text { Materials and } \\
\text { Methods: } \\
\text { Bioinformatic and } \\
\text { phylogenetic } \\
\text { analyses }\end{array}$} \\
\hline & & $\begin{array}{l}\text { NCBI } \\
\text { (https://www.ncbi } \\
\text {.nlm.nih.gov/) }\end{array}$ & NP_190664.1 & \\
\hline
\end{tabular}


bioRxiv preprint doi: https://doi.org/10.1101/2020.05.15.097584; this version posted May 16,2020 . The copyright holder for this preprint (which was not certified by peer review) is the author/funder, who has granted bioRxiv a license to display the preprint in perpetuity. It is made available under aCC-BY 4.0 International license.

\begin{tabular}{|c|c|c|c|c|}
\hline \multirow[t]{3}{*}{$\begin{array}{l}\text { Gene }(N . \\
\text { benthamiana) }\end{array}$} & \multirow[t]{3}{*}{ NbZAR1 } & $\begin{array}{l}\text { N.benthamiana } \\
\text { Genome v0.4.4 } \\
\text { (https://solgenomi } \\
\text { cs.net/) }\end{array}$ & NbS00000462g0011 & \multirow{3}{*}{$\begin{array}{l}\text { Materials and } \\
\text { Methods: } \\
\text { Bioinformatic and } \\
\text { phylogenetic } \\
\text { analyses }\end{array}$} \\
\hline & & $\begin{array}{l}\text { N.benthamiana } \\
\text { Genome v1.0.1 } \\
\text { (https://solgenomi } \\
\text { cs.net/) }\end{array}$ & $\begin{array}{l}\text { Niben101Scf17398g0 } \\
0012\end{array}$ & \\
\hline & & $\begin{array}{l}\text { NCBI } \\
\text { (https://www.ncbi } \\
\text {.nlm.nih.gov/) }\end{array}$ & AXY05280.1 & \\
\hline \multirow[t]{2}{*}{$\begin{array}{l}\text { Gene }(N . \\
\text { benthamiana) }\end{array}$} & \multirow[t]{2}{*}{ NbZAR2 } & $\begin{array}{l}\text { N.benthamiana } \\
\text { Genome v0.4.4 } \\
\text { (https://solgenomi } \\
\text { cs.net/) }\end{array}$ & NbS00013646g0007 & \multirow[t]{2}{*}{$\begin{array}{l}\text { Materials and } \\
\text { Methods: } \\
\text { Bioinformatic and } \\
\text { phylogenetic } \\
\text { analyses }\end{array}$} \\
\hline & & $\begin{array}{l}\text { N.benthamiana } \\
\text { Genome v1.0.1 } \\
\text { (https://solgenomi } \\
\text { cs.net/) }\end{array}$ & $\begin{array}{l}\text { Niben101Scf00383g0 } \\
3003 \\
\text { Niben101Scf00383g0 } \\
3004\end{array}$ & \\
\hline \multirow[t]{2}{*}{$\begin{array}{l}\text { Gene (Solanum } \\
\text { lycopersicum) }\end{array}$} & \multirow[t]{2}{*}{ SIZAR1 } & $\begin{array}{l}\text { Tomato ITAG } \\
\text { release } 2.40 \\
\text { (https://solgenomi } \\
\text { cs.net/) }\end{array}$ & Solyc02g084890 & \multirow[t]{2}{*}{$\begin{array}{l}\text { Materials and } \\
\text { Methods: } \\
\text { Bioinformatic and } \\
\text { phylogenetic } \\
\text { analyses }\end{array}$} \\
\hline & & $\begin{array}{l}\text { NCBI } \\
\text { (https://www.ncbi } \\
\text {.nlm.nih.gov/) }\end{array}$ & XP_004232433.1 & \\
\hline \multirow[t]{2}{*}{$\begin{array}{l}\text { Gene (Manihot } \\
\text { esculenta) }\end{array}$} & \multirow[t]{2}{*}{ MeZAR1 } & $\begin{array}{l}\text { Manihot esculenta } \\
\text { v7.1 } \\
\text { (https://phytozom } \\
\text { e- } \\
\text { next.jgi.doe.gov/)) }\end{array}$ & Manes.02G097400 & \multirow[t]{2}{*}{$\begin{array}{l}\text { Materials and } \\
\text { Methods: } \\
\text { Bioinformatic and } \\
\text { phylogenetic } \\
\text { analyses }\end{array}$} \\
\hline & & $\begin{array}{l}\text { NCBI } \\
\text { (https://www.ncbi } \\
\text {.nlm.nih.gov/) }\end{array}$ & P_021604862.1 & \\
\hline \multirow[t]{2}{*}{$\begin{array}{l}\text { Gene (Beta } \\
\text { vulgaris) }\end{array}$} & \multirow[t]{2}{*}{ BvZAR1 } & $\begin{array}{l}\text { RefBeet-1.2 } \\
\text { (http://bvseq.molg } \\
\text { en.mpg.de/index.s } \\
\text { html) }\end{array}$ & Bv9_203570_geqf.t1 & \multirow{2}{*}{$\begin{array}{l}\text { Materials and } \\
\text { Methods: } \\
\text { Bioinformatic and } \\
\text { phylogenetic } \\
\text { analyses }\end{array}$} \\
\hline & & $\begin{array}{l}\text { NCBI } \\
\text { (https://www.ncbi } \\
\text {.nlm.nih.gov/) }\end{array}$ & XP_010688776.1 & \\
\hline $\begin{array}{l}\text { Recombinant } \\
\text { DNA reagent }\end{array}$ & $\begin{array}{l}\text { ZAR1 plasmid } \\
\text { collection }\end{array}$ & This paper & pZA1-52 & $\begin{array}{l}\text { Materials and } \\
\text { Methods: Plasmid } \\
\text { constructions }\end{array}$ \\
\hline
\end{tabular}




\section{Plant growth conditions}

Wild type and mutant $N$. benthamiana were propagated in a glasshouse and, for most experiments, were grown in a controlled growth chamber with temperature $22-25^{\circ} \mathrm{C}$, humidity $45-65 \%$ and $16 / 8$-h light/dark cycle.

\section{Bioinformatic and phylogenetic analyses}

We used NLR-parser (Steuernagel et al., 2015) to identify NLR sequences from the protein databases of tomato (Sol Genomics Network, Tomato ITAG release 2.40), N. benthamiana (Sol Genomics Network, N. benthamiana Genome v0.4.4), Arabidopsis (https://www.araport.org/, Araport11), cassava (https://phytozome-next.jgi.doe.gov/, Phytozome v13, Manihot esculenta v7.1) and sugar beet (http://bvseq.molgen.mpg.de/index.shtml, RefBeet-1.2). The obtained NLR sequences from NLR-parser, were aligned using MAFFT v. 7 (Katoh and Standley, 2013), and the protein sequences that lacked the p-loop motif were discarded to make the NLR dataset (Figure 1-source data 1). The gaps in the alignments were deleted manually in MEGA7 (Kumar et al., 2016) and the NB-ARC domains were used for generating phylogenetic trees (Figure 1-source data 2). The neighbour-joining tree was made using MEGA7 with JTT model and bootstrap values based on 100 iterations (Figure 1-source data 3). Amino acid sequences of ZAR1 orthologs and the percent identity are listed in Figure 1-figure supplement 1 -source data 1 and -source data 2 .

To calculate the phylogenetic (patristic) distance, we used Python script based on DendroPy (Sukumaran and Mark, 2010). We calculated patristic distances from each CC-NLR to the other CC-NLRs on the phylogenetic tree (Figure 1-source data 3) and extracted the distance between CC-NLRs of Arabidopsis or N. benthamiana to the closest NLR from the other plant species. The script used for the patristic distance calculation is available from GitHub (https://github.com/slt666666/Phylogenetic_distance_plot).

\section{Plasmid constructions}

For Golden Gate cloning system, wild-type and MHD mutant clones of AtZAR1 and NbZAR1 were synthesized through GENEWIZ Standard Gene Synthesis with synonymous mutations to Bpil restriction enzyme sites. To generate MADA motif mutants of AtZAR1 and NbZAR1, the leucine (L) 17 in the MADA motif was substituted to glutamic acid (E) by site-directed mutagenesis using Phusion High-Fidelity DNA Polymerase (Thermo Fisher). To make AtZAR1 and NbZAR1 clones for C-terminal tagging, the stop codons were removed by PCR using Phusion High-Fidelity DNA Polymerase (Thermo Fisher). Primers used for the site-directed mutagenesis and removing stop codon were listed in Supplementary file 1. All wild-type and mutant cording sequences were cloned into pCR8/GW/D-TOPO (Invitrogen) as level 0 modules (Weber et al., 2011), namely pZA1-16 (Table 1). The level 0 plasmids were then used for Golden Gate assembly with or without C-terminal tag modules, pICSL50009 (6xHA, Addgene no. 50309), pICSL50010 (4xMyc, Addgene no. 50310) or pICSL50034 (eGFP, TSL SynBio) into the binary vector pICH86988 (Engler et al., 2014), namely pZA17-52 (Table 1).

\section{Transient gene-expression and cell death assays}


Transient expression of ZAR1 wild-type and mutants in N. benthamiana were performed by agroinfiltration according to methods described by Bos et al. (2006). Briefly, four-weeks old $N$. benthamiana plants were infiltrated with $A$. tumefaciens strains carrying the binary expression plasmids. A. tumefaciens suspensions were prepared in infiltration buffer $(10 \mathrm{mM}$ $\mathrm{MES}, 10 \mathrm{mM} \mathrm{MgCl}$, and $150 \mu \mathrm{M}$ acetosyringone, $\mathrm{pH}$ 5.6) and were adjusted to $\mathrm{OD}_{600}=0.5$. Macroscopic cell death phenotypes were scored according to the scale of Segretin et al. (2014) modified to range from 0 (no visible necrosis) to 7 (fully confluent necrosis).

\section{Protein immunoblotting}

Protein samples were prepared from six discs ( $8 \mathrm{~mm}$ diameter) cut out of $N$. benthamiana leaves at 2 days after agroinfiltration and were homogenised in extraction buffer $[10 \%$ glycerol, 25 mM Tris-HCl, pH 7.5, 1 mM EDTA, 150 mM NaCl, 2\% (w/v) PVPP, $10 \mathrm{mM} \mathrm{DTT,} \mathrm{1x}$ protease inhibitor cocktail (SIGMA), 0.5\% IGEPAL (SIGMA)]. The supernatant obtained after centrifugation at $12,000 \mathrm{xg}$ for $10 \mathrm{~min}$ was used for SDS-PAGE. Immunoblotting was performed with HA-probe (F-7) HRP (Santa Cruz Biotech), c-Myc (9E10) HRP (Santa Cruz Biotech) or GFP (B-2) HRP (Santa Cruz Biotech) in a 1:5,000 dilution. Equal loading was checked by taking images of the stained PVDF membranes with Pierce Reversible Protein Stain Kit (\#24585, Thermo Fisher).

\section{Plasmid distribution}

All pZA plasmids will be available through Addgene.

\section{ACKNOWLEDGEMENTS}

We are thankful to several colleagues for discussions and ideas. We thank Mark Youles of TSL SynBio for invaluable technical support. H.A. was funded by the Japan Society for the Promotion of Science (JSPS). This work was funded by the Gatsby Charitable Foundation, Biotechnology and Biological Sciences Research Council (BBSRC, UK), and European Research Council (ERC; NGRB and BLASTOFF projects).

\section{AUTHOR CONTRIBUTIONS}

S.K. and H.A. designed the research, supervised the work and wrote the paper; A.H., T.S and H.A. performed research.

\section{DECLARATION OF INTERESTS}

S.K. receives funding from industry on NLR biology. 
Table 1. Golden Gate Plasmid resources prepared in this study.

\begin{tabular}{|c|c|c|c|}
\hline Plasmids & Relevant features & $\begin{array}{l}\text { Bacterial } \\
\text { selection }\end{array}$ & Usage \\
\hline pZA1 & $\begin{array}{l}\text { Golden Gate compatible (GG_) wild-type AtZAR1 with STOP } \\
\text { codon }\end{array}$ & $\mathrm{Spc}^{r}$ & Level 0 \\
\hline pZA2 & GG_AtZAR1 $1^{\text {D489v }}$ with STOP codon & $\mathrm{Spc}^{r}$ & Level 0 \\
\hline pZA3 & GG_AtZAR1 ${ }^{\text {L17E }}$ with STOP codon & $\mathrm{Spc}^{r}$ & Level 0 \\
\hline pZA4 & GG_AtZAR1 $1^{\mathrm{L17E} / \mathrm{D} 489 \mathrm{~V}}$ with STOP codon & $\mathrm{Spc}^{r}$ & Level 0 \\
\hline pZA5 & GG_wild-type NbZAR1 with STOP codon & $\mathrm{Spc}^{r}$ & Level 0 \\
\hline pZA6 & GG_NbZAR1 ${ }^{\text {D481V }}$ with STOP codon & $\mathrm{Spc}^{r}$ & Level 0 \\
\hline pZA7 & GG_NbZAR1 ${ }^{\text {L17E }}$ with STOP codon & $\mathrm{Spc}^{r}$ & Level 0 \\
\hline pZA8 & GG_NbZAR1 $1^{\text {L17E/D481V }}$ with STOP codon & $\mathrm{Spc}^{r}$ & Level 0 \\
\hline pZA9 & GG_wild-type AtZAR1 without STOP codon & $\mathrm{Spc}^{r}$ & Level 0 \\
\hline pZA10 & GG_AtZAR1 $1^{\mathrm{D} 489 \mathrm{~V}}$ without STOP codon & $\mathrm{Spc}^{r}$ & Level 0 \\
\hline pZA11 & GG_AtZAR1 $1^{\text {L17E }}$ without STOP codon & $\mathrm{Spc}^{r}$ & Level 0 \\
\hline pZA12 & GG_AtZAR1 ${ }^{\text {L17E/D489V }}$ without STOP codon & $\mathrm{Spc}^{\mathrm{r}}$ & Level 0 \\
\hline pZA13 & GG_wild-type NbZAR1 without STOP codon & $\mathrm{Spc}^{r}$ & Level 0 \\
\hline pZA14 & GG_NbZAR1 $1^{\mathrm{D} 481 \mathrm{~V}}$ without STOP codon & $\mathrm{Spc}^{r}$ & Level 0 \\
\hline pZA15 & GG_NbZAR1 ${ }^{\text {L17E }}$ without STOP codon & $\mathrm{Spc}^{r}$ & Level 0 \\
\hline pZA16 & GG_NbZAR1 $1^{\mathrm{L17E} / \mathrm{D} 481 \mathrm{~V}}$ without STOP codon & $\mathrm{Spc}^{r}$ & Level 0 \\
\hline pZA17 & GG_wild-type AtZAR1, $\mathrm{Km}^{\mathrm{r}}$ plant selection marker & $\mathrm{Km}^{\mathrm{r}}$ & Level 2 \\
\hline pZA18 & GG_AtZAR1 ${ }^{\mathrm{D} 489 \mathrm{~V}}, \mathrm{Km}^{\mathrm{r}}$ plant selection marker & $\mathrm{Km}^{\mathrm{r}}$ & Level 2 \\
\hline pZA19 & GG_AtZAR1 ${ }^{\mathrm{L17E}}, \mathrm{Km}^{\mathrm{r}}$ plant selection marker & $\mathrm{Km}^{\mathrm{r}}$ & Level 2 \\
\hline pZA20 & GG_AtZAR1 ${ }^{\mathrm{L} 17 \mathrm{D} / \mathrm{D} 489 \mathrm{~V}}, \mathrm{Km}^{\mathrm{r}}$ plant selection marker & $\mathrm{Km}^{\mathrm{r}}$ & Level 2 \\
\hline pZA25 & GG_wild-type NbZAR1, $\mathrm{Km}^{\mathrm{r}}$ plant selection marker & $\mathrm{Km}^{\mathrm{r}}$ & Level 2 \\
\hline pZA26 & GG_NbZAR1 ${ }^{\mathrm{D} 481 \mathrm{~V}}, \mathrm{Km}^{\mathrm{r}}$ plant selection marker & $\mathrm{Km}^{\mathrm{r}}$ & Level 2 \\
\hline pZA27 & GG_NbZAR1 ${ }^{\mathrm{L} 17 \mathrm{E}}, \mathrm{Km}^{\mathrm{r}}$ plant selection marker & $\mathrm{Km}^{\mathrm{r}}$ & Level 2 \\
\hline pZA28 & GG_NbZAR1 ${ }^{L 17 E / D 481 V}, \mathrm{Km}^{r}$ plant selection marker & $\mathrm{Km}^{\mathrm{r}}$ & Level 2 \\
\hline
\end{tabular}

$\mathrm{Spc}^{\mathrm{r}}$ : spectinomycin-resistant, $\mathrm{Km}^{\mathrm{r}}$ : kanamycin-resistant.

Table 1. Continued. 


\begin{tabular}{|c|c|c|c|}
\hline Plasmids & Relevant features & $\begin{array}{l}\text { Bacterial } \\
\text { selection }\end{array}$ & Usage \\
\hline pZA29 & GG_wild-type AtZAR1-4xMyc, $\mathrm{Km}^{r}$ plant selection marker & $\mathrm{Km}^{\mathrm{r}}$ & Level 2 \\
\hline pZA30 & GG_AtZAR1 $1^{\text {D489v }}-4 \times M y c, \mathrm{Km}^{\mathrm{r}}$ plant selection marker & $\mathrm{Km}^{\mathrm{r}}$ & Level 2 \\
\hline pZA31 & GG_AtZAR1 ${ }^{\mathrm{L} 17 \mathrm{E}}-4 \mathrm{xMyc}, \mathrm{Km}^{\mathrm{r}}$ plant selection marker & $\mathrm{Km}^{\mathrm{r}}$ & Level 2 \\
\hline pZA32 & GG_AtZAR1 ${ }^{\mathrm{L17E} / \mathrm{D} 489 \mathrm{~V}}-4 \mathrm{xMyc}, \mathrm{Km}^{\mathrm{r}}$ plant selection marker & $\mathrm{Km}^{\mathrm{r}}$ & Level 2 \\
\hline pZA33 & GG_wild-type NbZAR1-4xMyc, $\mathrm{Km}^{\mathrm{r}}$ plant selection marker & $\mathrm{Km}^{\mathrm{r}}$ & Level 2 \\
\hline pZA34 & GG_NbZAR1 ${ }^{D 481 v_{-}} 4 x M y c, \mathrm{Km}^{\mathrm{r}}$ plant selection marker & $\mathrm{Km}^{\mathrm{r}}$ & Level 2 \\
\hline pZA35 & 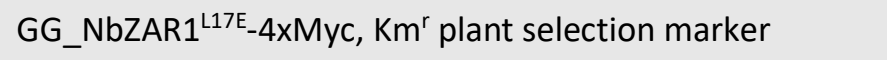 & $\mathrm{Km}^{\mathrm{r}}$ & Level 2 \\
\hline pZA36 & 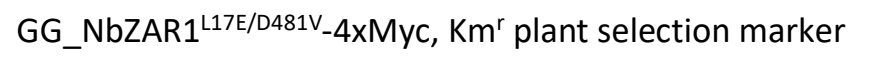 & $\mathrm{Km}^{\mathrm{r}}$ & Level 2 \\
\hline pZA37 & GG_wild-type AtZAR1-6xHA, $\mathrm{Km}^{\mathrm{r}}$ plant selection marker & $\mathrm{Km}^{\mathrm{r}}$ & Level 2 \\
\hline pZA38 & GG_AtZAR1 ${ }^{\text {D489v }}-6 x H A, \mathrm{Km}^{r}$ plant selection marker & $\mathrm{Km}^{\mathrm{r}}$ & Level 2 \\
\hline pZA39 & GG_AtZAR1 ${ }^{\mathrm{L} 17 \mathrm{E}}-6 \mathrm{xHA}, \mathrm{Km}^{\mathrm{r}}$ plant selection marker & $\mathrm{Km}^{r}$ & Level 2 \\
\hline pZA40 & GG_AtZAR1 ${ }^{\mathrm{L17E} / \mathrm{D} 489 \mathrm{~V}}-6 \mathrm{xHA}, \mathrm{Km}^{\mathrm{r}}$ plant selection marker & $\mathrm{Km}^{\mathrm{r}}$ & Level 2 \\
\hline pZA41 & GG_wild-type NbZAR1-6xHA, $\mathrm{Km}^{\mathrm{r}}$ plant selection marker & $\mathrm{Km}^{\mathrm{r}}$ & Level 2 \\
\hline pZA42 & 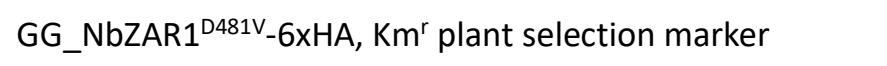 & $\mathrm{Km}^{\mathrm{r}}$ & Level 2 \\
\hline pZA43 & GG_NbZAR1 ${ }^{\text {L17E_}}-6 x H A, \mathrm{Km}^{r}$ plant selection marker & $\mathrm{Km}^{\mathrm{r}}$ & Level 2 \\
\hline pZA44 & GG_NbZAR1 $1^{\text {L17E/D481V }}-6 \times \mathrm{HA}, \mathrm{Km}^{\mathrm{r}}$ plant selection marker & $\mathrm{Km}^{\mathrm{r}}$ & Level 2 \\
\hline pZA45 & GG_wild-type AtZAR1-eGFP, $\mathrm{Km}^{r}$ plant selection marker & $\mathrm{Km}^{\mathrm{r}}$ & Level 2 \\
\hline pZA46 & 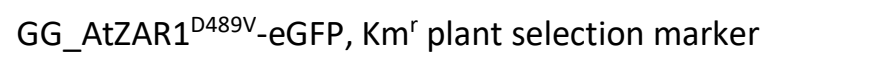 & $\mathrm{Km}^{\mathrm{r}}$ & Level 2 \\
\hline pZA47 & GG_AtZAR1 ${ }^{\mathrm{L} 17 \mathrm{E}}-\mathrm{eGFP}, \mathrm{Km}^{\mathrm{r}}$ plant selection marker & $\mathrm{Km}^{r}$ & Level 2 \\
\hline pZA48 & GG_AtZAR1 ${ }^{\mathrm{L17E} / \mathrm{D} 489 \mathrm{~V}}$-eGFP, $\mathrm{Km}^{\mathrm{r}}$ plant selection marker & $\mathrm{Km}^{\mathrm{r}}$ & Level 2 \\
\hline pZA49 & GG_wild-type NbZAR1-eGFP, $\mathrm{Km}^{\mathrm{r}}$ plant selection marker & $\mathrm{Km}^{\mathrm{r}}$ & Level 2 \\
\hline pZA50 & GG_NbZAR1 $1^{\mathrm{D} 481 \mathrm{~V}_{-}}$eGFP, $\mathrm{Km}^{\mathrm{r}}$ plant selection marker & $\mathrm{Km}^{r}$ & Level 2 \\
\hline pZA51 & GG_NbZAR1 ${ }^{\text {L17E }}$-eGFP, $\mathrm{Km}^{r}$ plant selection marker & $\mathrm{Km}^{r}$ & Level 2 \\
\hline pZA52 & 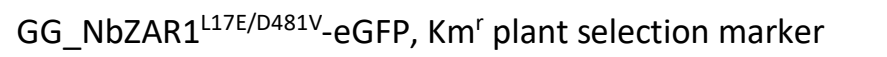 & $\mathrm{Km}^{\mathrm{r}}$ & Level 2 \\
\hline
\end{tabular}

$\mathrm{Spc}^{\mathrm{r}}$ : spectinomycin-resistant, $\mathrm{Km}^{\mathrm{r}}$ : kanamycin-resistant. 
bioRxiv preprint doi: https://doi.org/10.1101/2020.05.15.097584; this version posted May $16,2020$. The copyright holder for this preprint (which was not certified by peer review) is the author/funder, who has granted bioRxiv a license to display the preprint in perpetuity. It is made available under aCC-BY 4.0 International license.

\section{References}

Adachi H, Contreras MP, Harant A, Wu CH, Derevnina L, Sakai T, Duggan C, Moratto E, Bozkurt TO, Maqbool A, Win J, Kamoun S. 2019. An N-terminal motif in NLR immune receptors is functionally conserved across distantly related plant species. elife 8: e49956. doi: 10.7554/eLife.49956.

Bally J, Jung H, Mortimer C, Naim F, Philips JG, Hellens R, Bombarely A, Goodin MM, Waterhouse PM. 2018. The rise and rise of Nicotiana benthamiana: a plant for all reasons. Annu Rev Phytopathol 56: 405-426. doi: 10.1146/annurev-phyto080417-050141.

Baudin M, Hassan JA, Schreiber KJ, Lewis JD. 2017. Analysis of the ZAR1 immune complex reveals determinants for immunity and molecular interactions. Plant Physiol 174: 2038-2053. doi: 10.1104/pp.17.00441.

Baudin M, Schreiber KJ, Martin EC, Petrescu AJ, Lewis JD. 2019. Structure-function analysis of ZAR1 immune receptor reveals key molecular interactions for activity. Plant J 101: 352-370. doi: 10.1111/tpj.14547.

Bos JI, Kanneganti TD, Young C, Cakir C, Huitema E, Win J, Armstrong MR, Birch PR, Kamoun S. 2006. The C-terminal half of Phytophthora infestans RXLR effector AVR3a is sufficient to trigger R3a-mediated hypersensitivity and suppress INF1induced cell death in Nicotiana benthamiana. Plant J 48: 165-176. doi: 10.1111/j.1365-313X.2006.02866.x.

Engler C, Youles M, Gruetzner R, Ehnert TM, Werner S, Jones JD, Patron NJ, Marillonnet S. 2014. A golden gate modular cloning toolbox for plants. ACS Synth Bio/ 3: 839-843. doi: 10.1021/sb4001504.

Goodin MM, Zaitlin D, Naidu RA, Lommel SA. 2008. Nicotiana benthamiana: its history and future as a model for plantpathogen interactions. Mol Plant Microbe Interact 21: 1015-1026. doi: 10.1094/MPMI-21-8-1015.

Hu M, Qi J, Bi G, Zhou JM. 2020. Bacterial effectors induce oligomerization of immune receptor ZAR1 in vivo. Mol Plant pii: S1674-2052(20)30066-6. doi: 10.1016/j.molp.2020.03.004.

Katoh K, Standley DM. 2013. MAFFT multiple sequence alignment software version 7: improvements in performance and usability. Mol Biol Evol 30: 772-780. doi: 10.1093/molbev/mst010.

Kumar S, Stecher G, Tamura K. 2016. MEGA7: molecular evolutionary genetics analysis version 7.0 for bigger datasets. Mol Biol Evol 33: 1870-1874. doi: 10.1093/molbev/msw054.

Lewis JD, Wu R, Guttman DS, Desveaux D. 2010. Allele-specific virulence attenuation of the Pseudomonas syringae HopZ1a type III effector via the Arabidopsis ZAR1 resistance protein. PLoS Genet 6: e1000894. doi: 10.1371/journal.pgen.1000894.

Li L, Habring A, Wang K, Weigel D. 2020. Atypical resistance protein RPW8/HR triggers oligomerization of the NLR immune receptor RPP7 and autoimmunity. Cell Host Microbe 27: 405-417. doi: 10.1016/j.chom.2020.01.012.

Patron NJ, Orzaez D, Marillonnet S, Warzecha H, Matthewman C, Youles M, Raitskin O, Leveau A, Farré G, Rogers C, Smith A, Hibberd J, Webb AA, Locke J, Schornack S, Ajioka J, Baulcombe DC, Zipfel C, Kamoun S, Jones JD, Kuhn H, Robatzek S, Van Esse HP, Sanders D, Oldroyd G, Martin C, Field R, O'Connor S, Fox S, Wulff B, Miller B, Breakspear A, Radhakrishnan G, Delaux PM, Loqué D, Granell A, Tissier A, Shih P, Brutnell TP, Quick WP, Rischer H, Fraser PD, Aharoni A, Raines C, South $P F$, Ané JM, Hamberger BR, Langdale J, Stougaard J, Bouwmeester H, Udvardi M, Murray JA, Ntoukakis V, Schäfer $P$, Denby K, Edwards KJ, Osbourn A, Haseloff J. 2015. Standards for plant synthetic biology: a common syntax for exchange of DNA parts. New Phytol 208: 13-19. doi: 10.1111/nph.13532.

Segretin ME, Pais M, Franceschetti M, Chaparro-Garcia A, Bos JI, Banfield MJ, Kamoun S. 2014. Single amino acid mutations in the potato immune receptor R3a expand response to Phytophthora effectors. Mol Plant Microbe Interact 27: 624-637. doi: 10.1094/MPMI-02-14-0040-R.

Steuernagel B, Jupe F, Witek K, Jones JD, Wulff BB. 2015. NLR-parser: rapid annotation of plant NLR complements. Bioinformatics 31: 1665-1667. doi: 10.1093/bioinformatics/btv005.

Sukumaran J, Holder MT. 2010. DendroPy: a Python library for phylogenetic computing. Bioinformatics 26: 1569-1571. doi: 10.1093/bioinformatics/btq228.

Tameling WI, Vossen JH, Albrecht M, Lengauer T, Berden JA, Haring MA, Cornelissen BJ, Takken FL. 2006. Mutations in the NB-ARC domain of I-2 that impair ATP hydrolysis cause autoactivation. Plant Physiol 140: 1233-1245. doi: 10.1104/pp.105.073510.

Wang J, Wang J, Hu M, W Shan, Qi J, Wang G, Han Z, Qi Y, Gao N, Wang H-W, Zhou J-M, Chai J. 2019a. Ligand-triggered allosteric ADP release primes a plant NLR complex. Science 364: eaav5868. doi: 10.1126/science.aav5868.

Wang J, Hu M, Wang J, Qi J, Han Z, Wang G, Qi Y, Wang H-W, Zhou J-M, Chai J. 2019b. Reconstitution and structure of a plant NLR resistosome conferring immunity. Science 364: eaav5870. doi: 10.1126/science.aav5870.

Weber E, Engler C, Gruetzner R, Werner S, Marillonnet S. 2011. A modular cloning system for standardized assembly of multigene constructs. PLoS One 6: e16765. doi: 10.1371/journal.pone.0016765. 


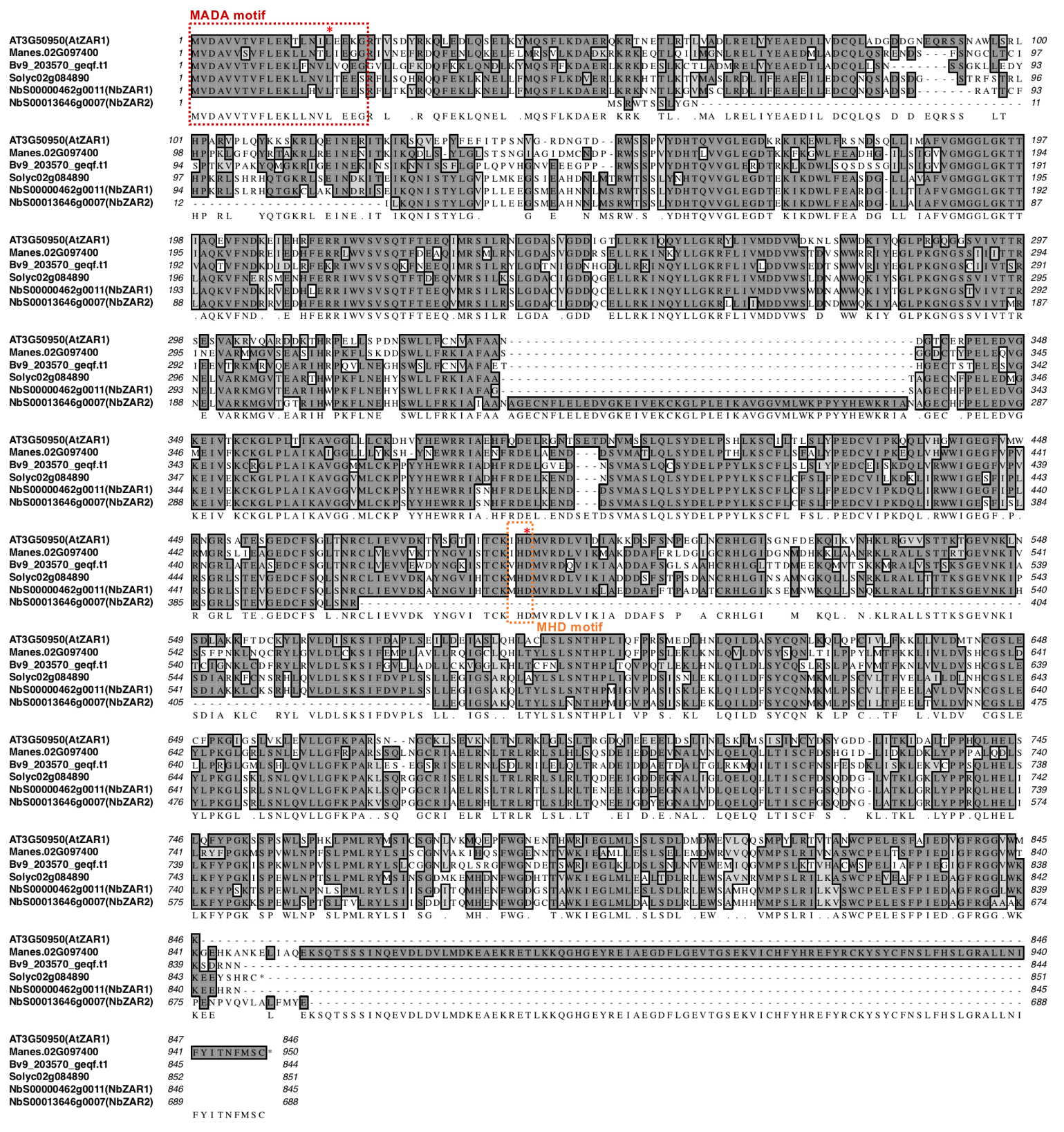

Figure 1-figure supplement 1. Sequence alignment of full-length ZAR1 ortholog proteins. Amino acid sequences of ZAR1 orthologs were aligned by ClustalW program. MADA and MHD motif sequences are marked with red and orange dot boxes, respectively. Red asterisks indicate substitution sites for MADA and MHD mutations. 


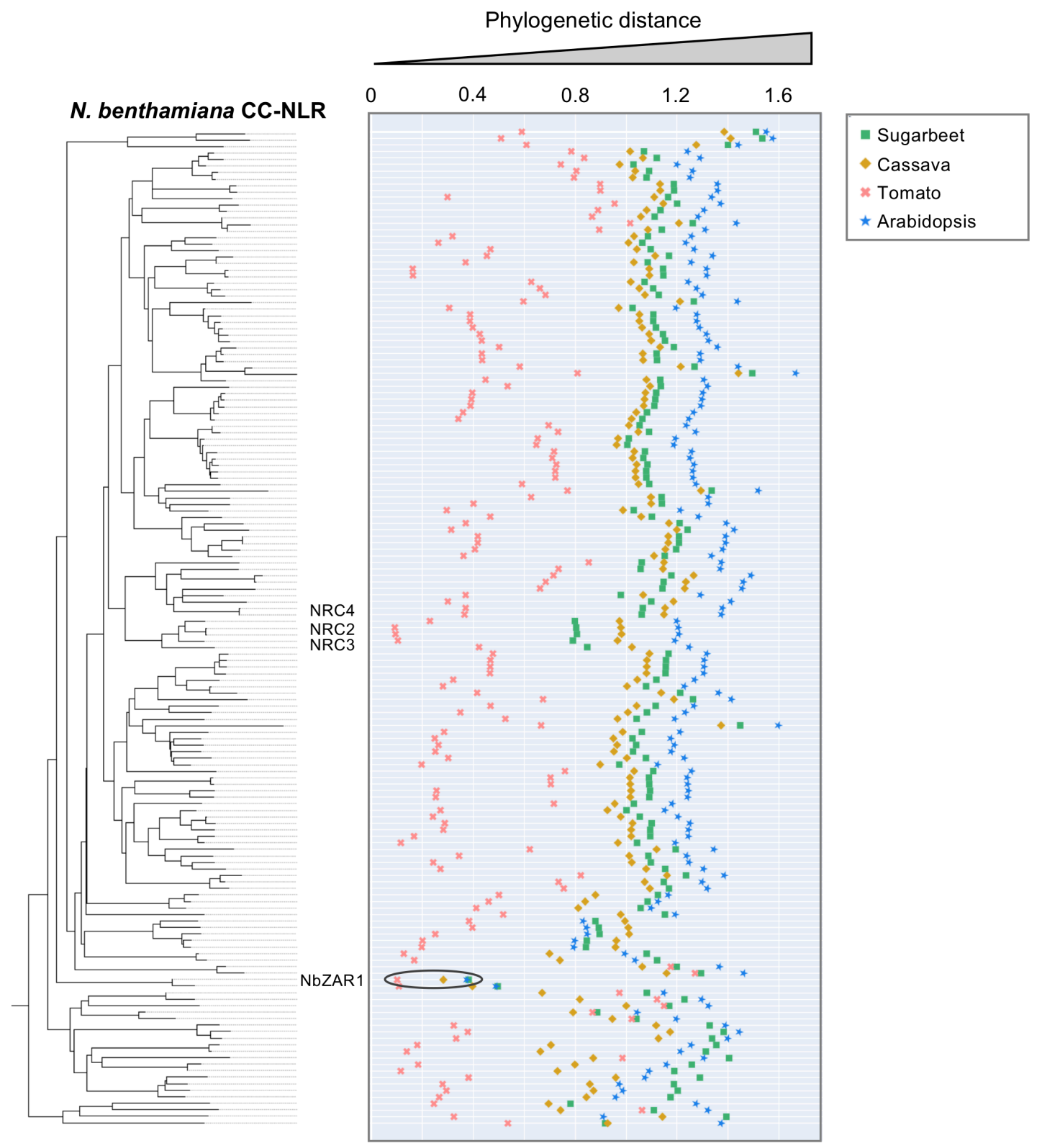

Figure $\mathbf{1}$-figure supplement $\mathbf{2}$. NbZAR1 is highly conserved across dicot species. The phylogenetic (patristic) distance of two CC-NLR nodes between $N$. benthamiana and the closest NLR from the other plant species were calculated from the NB-ARC phylogenetic tree in Figure $1 \mathrm{~A}$. The closest patristic distances are plotted with different colours based on plant species. 


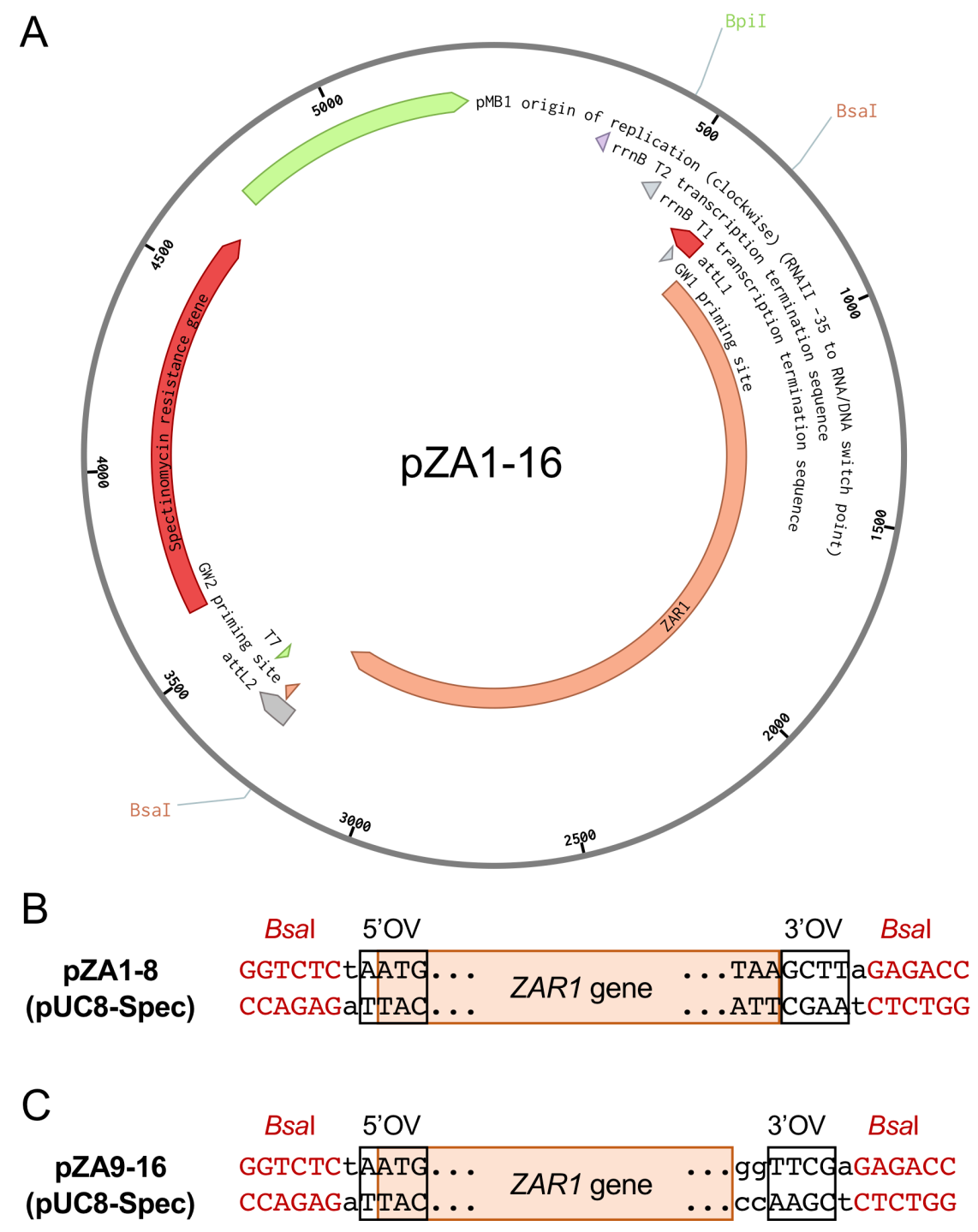

Table 1-figure supplement 1. Golden Gate Level 0 modules of AtZAR1 and NbZAR1 genes. (A) AtZAR1 and NbZAR1 wild-type and the mutant genes were cloned in the pUC8-Spec vector (pZA1-16). The plasmid map was made with Benchling software. (B) ZAR1 genes were cloned with the stop codon in pZA1-8 plasmids. (C) ZAR1 genes were cloned without the stop codon for C-terminal tag fusion (pZA9-16). Bsal restriction enzyme sites for Golden Gate assembly are shown as red characters. $5^{\prime}$ and $3^{\prime}$ overhang sequences after Bsal digestion are described as $5^{\prime} \mathrm{OV}$ and $3^{\prime} \mathrm{OV}$, respectively. 


\section{Supplementary files}

Supplementary file 1. Primers Used for generating ZAR1 Golden Gate Level 0 constructs.

\section{Source data files}

Figure 1-source data 1. Amino acid sequences of full-length NLRs in the NLR dataset. The 829 NLR sequences used in this study.

Figure 1-source data 2. Amino acid sequences for NLR phylogenetic tree. NB-ARC domain sequences used for phylogenetic analysis are shown with the IDs, N. benthamiana (NbS-), tomato (Solyc-), sugar beet (Bv-), Arabidopsis (AT-) and cassava (Manes-).

Figure 1-source data 3. NLR phylogenetic tree file. The phylogenetic tree was saved in newick file format.

Figure 1-figure supplement 1-source data 1. Amino acid sequences of ZAR1 orthologs. The N-terminal 28 amino acids (MAMRNQLYILESASQFPWAAFQKSEAEE) of SIZAR1 (Solyc02g084890) were removed due to potential mis-annotation.

Figure 1-figure supplement 1-source data 2. Percent identity matrix of ZAR1 orthologs by Clustal2.1. 